\title{
EFFECT OF VISUAL CUES ON STATIC ADVERTISEMENT VIEWING PATTERNS
}

\author{
Lina Pileliene ${ }^{1}, \mathrm{PhD}$; Viktorija Grigaliunaite ${ }^{2}$ \\ ${ }^{1,2}$ Vytautas Magnus University
}

\begin{abstract}
In conditions of hard competition in consumer products markets, advertising becomes one of the main measures helping business companies to encourage people to choose their products. In business as well as in scientific societies, the elements enhancing advertising effectiveness becomes one of the most discussed questions. Accordingly, this article deals with this topic by solving a scientific problem - is there and what is the effect of visual cues on static advertisement viewing patterns? The aim of the research is to determine the effect of visual cues on static advertisement viewing patterns. The neuromarketing research method - eyetracking - is performed to determine the most effective visual cues in static advertising; managerial implications regarding the usage of visual cues are provided based on the research results.
\end{abstract}

Key words: advertising, advertising effectiveness, eye tracking, visual cues.

JEL code: $M 31, M 37$

\section{Introduction}

Advertising is a common practice used by companies to inform, persuade and remind consumers about the products and services. If well performed, it can visibly elevate sales and revenues. However, being used massively, many advertisements are facing ignorance or remain unnoticed by potential consumers. Advertising research is keeping its popularity for many years. According to Eisend M. and Tarrahi F. (2016), practitioners and scholars are concerned about whether and to what degree advertising influences consumers, what consumer reactions advertising can evoke, and how these reactions are related. Patrick V. M. and Hagtvedt H. (2011) emphasize that the effectiveness of an advertisement is a function of what is said and how it is said; therefore, several creative elements come together to form a successful advertisement. The determination of latter elements and their combinations becomes an important task for advertisers achieving to break through the information clutter.

A particular composition of elements in static advertisement is called advertising layout. According to Chamblee R. and Sandler D. M. (1992), layouts represent the culmination of all the components that make up print (in our case, static) advertisements. Evidently, some layouts are superior compared with others (Pileliene L. and Grigaliunaite V., 2016a). Previous research (Pileliene L. and Grigaliunaite V., 2016b) revealed that more complex advertisements received more consumers' visual attention than less complex ones; however, consumers' visual attention to a brand (or logotype) presented in an advertisement was decreasing when advertising complexity increased. Despite the valid research results obtained in standard conditions, the existence of extraordinary ways to elevate advertising effectiveness in terms of extending the brand viewing time cannot be denied. As one of such ways, visual cues can be named. The problem solved by the research is stated by the question: is there and what is the effect of visual cues on static advertisement viewing patterns? This article aims to determine the effect of visual cues on static advertisement viewing patterns.

Many methods for assessing advertising effectiveness were elaborated, validated and improved. Pozharliev R., Verbeke W. I. and Bagozzi R. P. (2017) emphasize that traditional methods for predicting the success of advertising are based on selfreports and largely depend on the willingness and ability of consumers to describe their levels of attention, emotions, preferences, or future buying behaviour in relation to the marketing campaign to which they have been exposed. 
Therefore, the use of neuroscientific advertising research is emerging. To get more precise results, eye-tracking experiment was provided.

\section{Research results and discussion 1. Methodology of the research}

The analysis and synthesis of scientific literature reveal that directional visual cues are powerful means for orienting consumer's visual attention to the most important parts of the advertisement's layout (e.g. brand presented in the advertisement) (Hutton, S. B. and Nolte, S., 2011). Hence, directional visual cues in the advertisements are visual elements that direct consumer's visual attention toward the core elements of the message that organization wants consumers to see. One type that has a special status as an attentional cue is deictic gaze (Shepherd, V., 2010) - when someone in the advertisement is looking at something (e.g. brand or product), consumer brain acts reflexively and they start looking at that object as well. The other type of visual cues is pointing gestures (when someone in the advertisement is pointing with the hand or leg or somehow else at something) (Birmingham, E., Bischof, W. F. and Kingstone, A., 2009). This type of visual cues may also include pointing arrows, head position or body position. Deictic gaze and pointing arrows are widely discussed in the scientific literature (Birmingham, E., Bischof, W. F. and Kingstone, A., 2009; Hutton, S. B. and Nolte, S., 2011). Nevertheless, research regarding the type of visual cue when someone is holding and / or using something is scarce. Consequently, four categories of the advertisements with different types of visual cues are generated:

- Advertisements without cues (control);

- Advertisements with deictic gaze to a brand / product;

- Advertisements with pointing gestures / arrows to a brand / product;

- Advertisements where spokesperson is holding / using the product with the brand presented on it.

Based on the content analysis of real advertisements the grid of the experiment's advertisements was created with the description of three advertisements for each category (Table 1).

Table 1

The grid of experiment's advertisements

\begin{tabular}{|c|c|c|c|}
\hline \multirow{2}{*}{ Criteria } & \multicolumn{3}{|c|}{ Number of the advertisement } \\
\hline & 1 & 2 & 3 \\
\hline $\begin{array}{l}\text { Advertisements } \\
\text { without cues } \\
\text { (control) }\end{array}$ & $\begin{array}{l}\text { Spokesperson in the right } \\
\text { of the advertisements' } \\
\text { layout and the product with } \\
\text { the brand on it in the left of } \\
\text { the advertisements' layout }\end{array}$ & $\begin{array}{l}\text { Spokespersons in the left of } \\
\text { the advertisements' layout } \\
\text { and the product with the } \\
\text { brand on it in the right of } \\
\text { the advertisements' layout }\end{array}$ & $\begin{array}{l}\text { Spokes-characters in the } \\
\text { middle of the } \\
\text { advertisements' layout, } \\
\text { product with the brand on } \\
\text { it in the bottom of } \\
\text { advertisements' layout }\end{array}$ \\
\hline $\begin{array}{l}\text { Advertisements } \\
\text { with deictic gaze }\end{array}$ & $\begin{array}{l}\text { Spokesperson looking at } \\
\text { the product with the brand } \\
\text { on it }\end{array}$ & $\begin{array}{l}\text { Spokesperson looking at } \\
\text { the product with the brand } \\
\text { on it }\end{array}$ & $\begin{array}{l}\text { Spokesperson looking at } \\
\text { the product with the brand } \\
\text { on it }\end{array}$ \\
\hline $\begin{array}{l}\text { Advertisements } \\
\text { with pointing } \\
\text { gestures }\end{array}$ & $\begin{array}{l}\text { Spokesperson pointing } \\
\text { with hand to the product } \\
\text { with the brand on it }\end{array}$ & $\begin{array}{l}\text { Arrow pointing from the } \\
\text { spokes-character to the } \\
\text { product with the brand on } \\
\text { it }\end{array}$ & $\begin{array}{l}\text { Spokesperson pointing with } \\
\text { leg to the product with the } \\
\text { brand on it }\end{array}$ \\
\hline $\begin{array}{l}\text { Advertisements } \\
\text { with } \\
\text { holding/using } \\
\text { product }\end{array}$ & $\begin{array}{l}\text { Spokesperson holding in } \\
\text { the hand and using } \\
\text { (drinking) the product with } \\
\text { the brand on it }\end{array}$ & $\begin{array}{l}\text { Spokesperson holding in } \\
\text { the hand and using } \\
\text { (drinking) the product with } \\
\text { the brand on it }\end{array}$ & $\begin{array}{l}\text { Spokesperson holding in } \\
\text { the hand the product with } \\
\text { the brand on it }\end{array}$ \\
\hline
\end{tabular}


According to the latter grid, 12 static advertisements were created by the professionals (4 categories of advertisements, each category contained three advertisements in order to eliminate the possible biases) and approved by marketing experts. Hence, advertisements without cues (as a control) contain spokespersons or spokes-characters and the products with the brands on them without any directional cues. Advertisements in the category of deictic gaze visual cue contained spokespersons looking at the products with the brands on them. Advertisements with pointing gestures as visual cues contained spokespersons pointing with the hand or leg to the product with the brand on it and arrow pointing from the spokes-character to the product with the brand on it. Finally, advertisements where spokesperson was holding / using the product with the brand presented on it contained advertisements with spokesperson holding and / or using the product with the brand presented on it. In all of the advertisements, the advertised product was mineral water and the brands used on the products were created (not existing) in order to eliminate the influence of current attitudes towards existing brands.

All the advertisements were presented in the computer screen, one advertisement at once and the participants looked at the advertisements at their own pace, controlling the switch of the advertisements with the computer mouse. Between the advertisements the interstimulus of black screen appeared for 2 seconds in order to eliminate the influence of the previously seen advertisement's gaze trajectory. All the participants were told to just look at the advertisements as they would in real environment (participants were not told that the viewing patterns were analysed in order to get as reliable results as possible). Total of 12 participants ( 8 women) participated in the experiment that was held in January 2018. All of the participants were at the age group of 20-30 years with normal to normal-to-corrected vision.

Tobii Pro X2-30 screen-based eye tracker capturing gaze data at $30 \mathrm{~Hz}$ with the accuracy of $0.4^{\circ}$ was applied for the experiment. Each participant was calibrated before the experiment. For the analysis of eye tracing results, Tobii Studio v.3.2.3 software was used. Areas of interest for advertisements and brands presented on the products in the advertisements were created and time to first fixation to the brand as well as viewing time and fixation count to the advertisements and brands were calculated. IBM SPSS Statistics v. 20 software package was applied for the statistical analysis of the results obtained from the Tobii Studio v.3.2.3 software.

\section{Research results}

The analysis of the research results starts with the evaluation of time to first fixation on a brand in the advertisement (in seconds). This metric measure how long it takes before a participant fixates on the specified group of the areas of interest for the first time. In this case the specified group of the areas of interest is the brands presented in the advertisements of the defined category (advertisements without cues; advertisements with deictic gaze, advertisements with pointing gestures, and advertisements with holding / using product). Latter results are provided in Figure 1 with the average participants' time to first fixation to the brand. As it can be seen, in the advertisements where visual cues are the pointing gestures (arrow pointing or spokesperson pointing with hand / leg), the brands are seen the first. The category of the advertisements where the brands are seen later is holding / using product. Slightly later brands are first seen in the advertisements with deictic gaze. Finally, it takes the longest time to see the brands presented in the advertisements without visual cues. Hence, it can be stated that visual cues help to see the core of the message faster when compared to the advertisements without visual cues. 


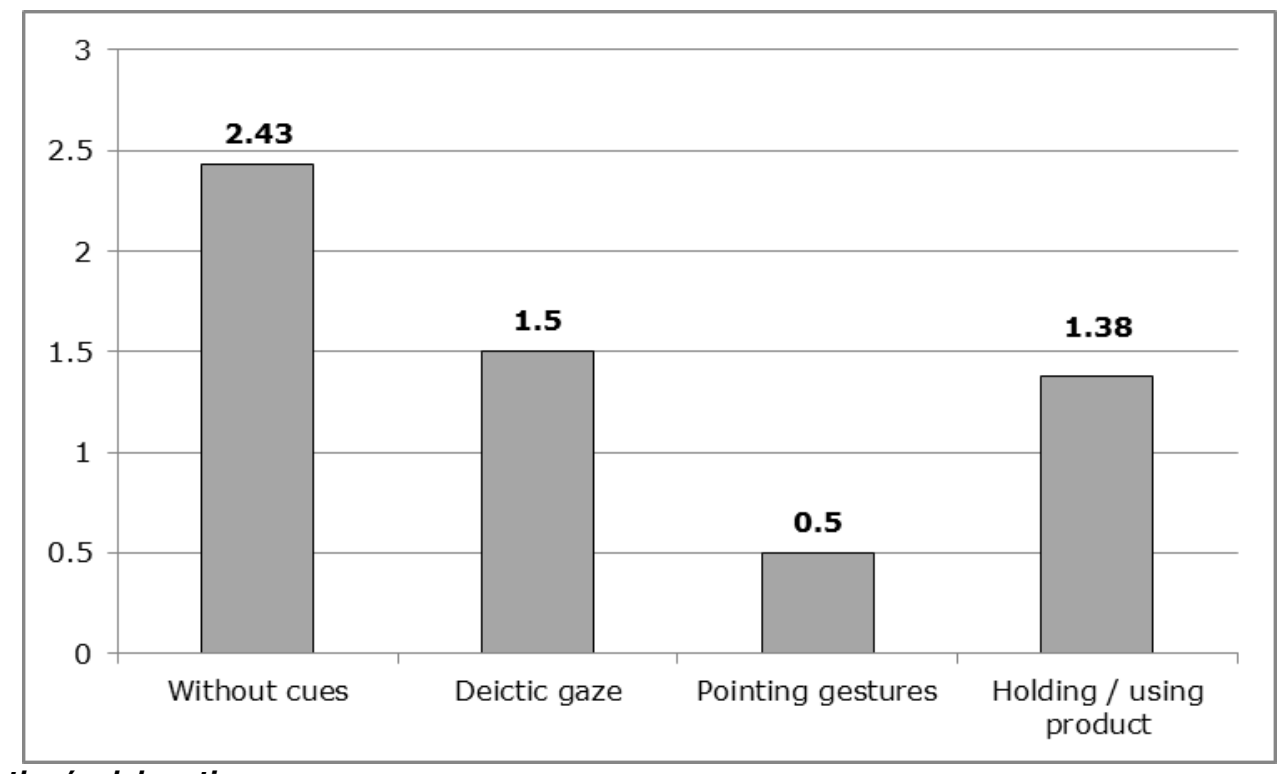

Source: author's elaboration

Fig. 1. Time to first fixation on a brand in the advertisement (in seconds)

The average of the participants' total fixation duration (in seconds) on the advertisements and brands showed in the advertisements is presented in Figure 2 below. As it can be seen, the advertisements where the spokesperson is holding / using the product attract the most participants' visual attention. Moreover, the brands presented in these advertisements also attract the most visual attention.

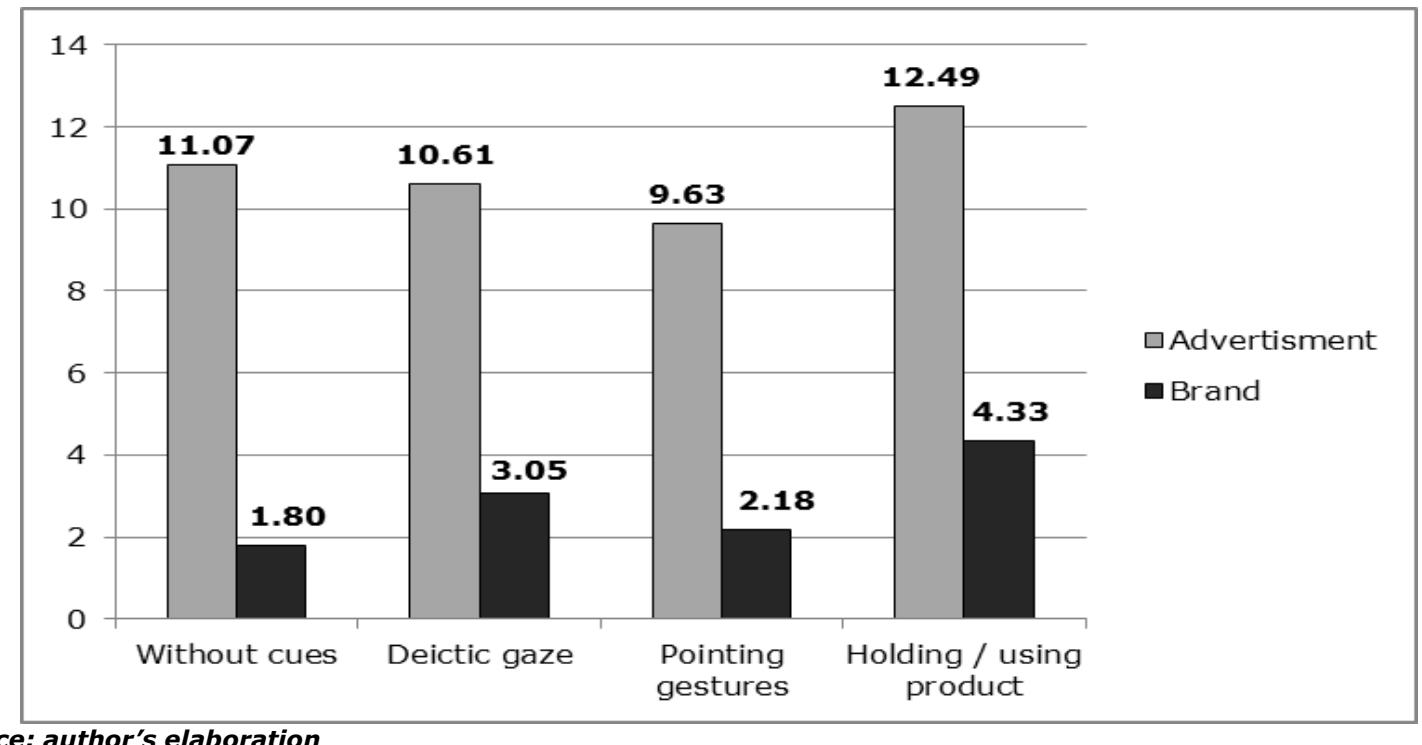

Source: author's elaboration

Fig. 2. Total fixation duration (in seconds) on the advertisements and brands presented in the advertisements

The advertisements without visual cues are in the second place regarding attracted visual attention to the advertisements. Nevertheless, brands presented in these advertisements attract least participants' visual attention. It can be stated, that without visual cues the possibility that consumers will notice the brand presented in the advertisement decreases. The advertisements with deictic gaze to the product and brand presented on the product are in the third place regarding attracted visual attention to the advertisements, but in the second place regarding attracted visual attention to the brands presented in the advertisements. Finally, advertisements 
with pointing gestures to the product and brand presented on the product attract least visual attention, but are in the third place regarding attracted visual attention to the brands presented in the advertisements. Consequently, it could be stated that visual cues do not necessarily make advertisement itself more visually interesting as advertisements without visual cues still attract attention, but they definitely enhance the possibility that brand presented in the advertisement will be seen and taken into consideration as brands presented in the advertisements with any visual cues attract more visual attention than brands presented in the advertisements without visual cues.

Latter results are substantiated by the participants' average fixation count (number of fixations in times) within the advertisements and brands presented in the advertisements that can be seen in Figure 3. The advertisements where the spokesperson is holding / using the product had the most fixations on the advertisement as well as on the brand. The advertisements with deictic gaze to the brand are in the second place regarding fixation count to the brand and in the third place regarding fixation count to the advertisement. Advertisements with pointing gestures to the brand are in the third place regarding fixation count to the brand and in the fourth place regarding fixation count to the advertisement. Finally, advertisements without visual cues are in the second place regarding fixation count to the advertisement, but in the last place regarding fixation count to the brand.

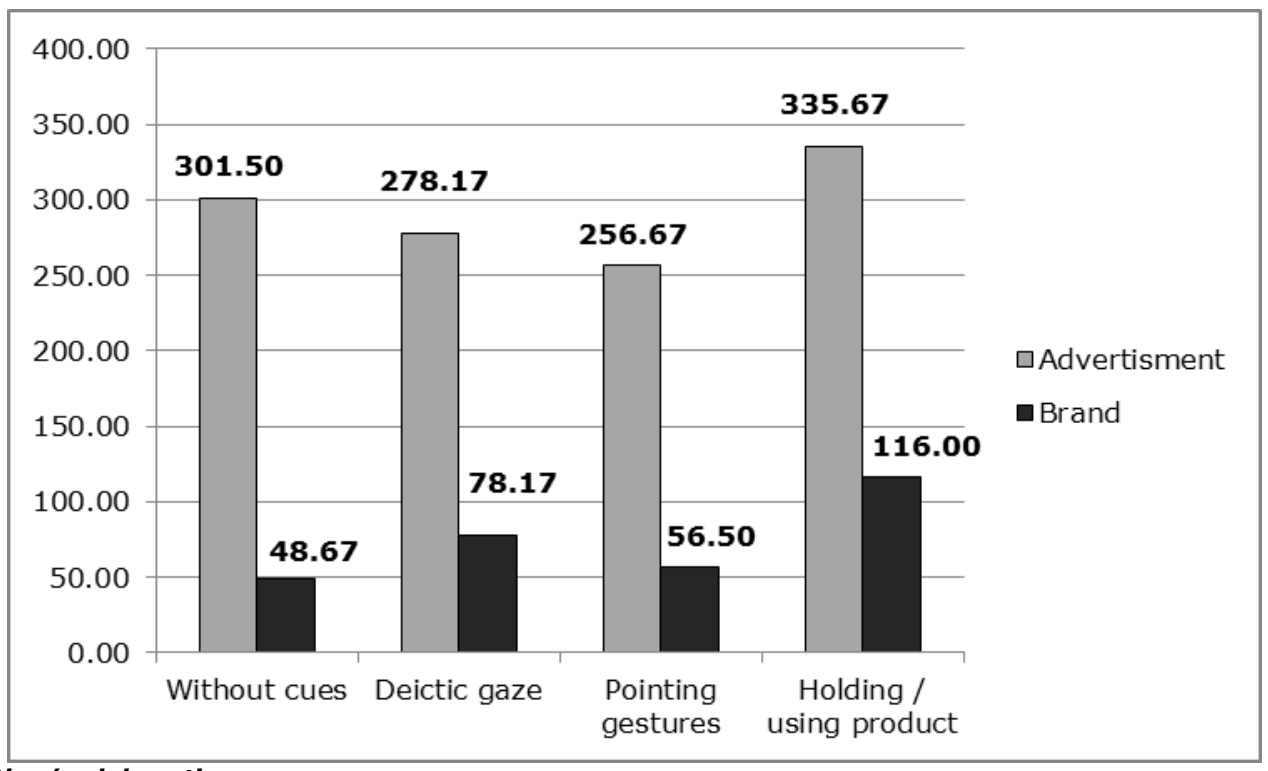

Source: author's elaboration

Fig. 3. Fixation count (times) on the advertisements and brands presented in the advertisements

Consequently, when measuring brand viewing time as a percent from advertisement's viewing time (Figure 4), it can be seen that visual cues of spokesperson holding / using the product and deictic gaze attract most visual attention to the brand when watching at the advertisement, respectively 35 percent and 29 percent of advertisement's viewing time. When pointing gestures to the brand are used in the advertisement, brand viewing time is 23 percent from the advertisement's viewing time. Finally, when there are no visual cues in the advertisement, brand viewing time is 16 percent from the advertisement's viewing time. Bearing in mind that if advertisements' viewing time is a few seconds, then there is a possibility that brand presented in 
the advertisement without visual cues cannot pass the filter of attention as its viewing time is too short.

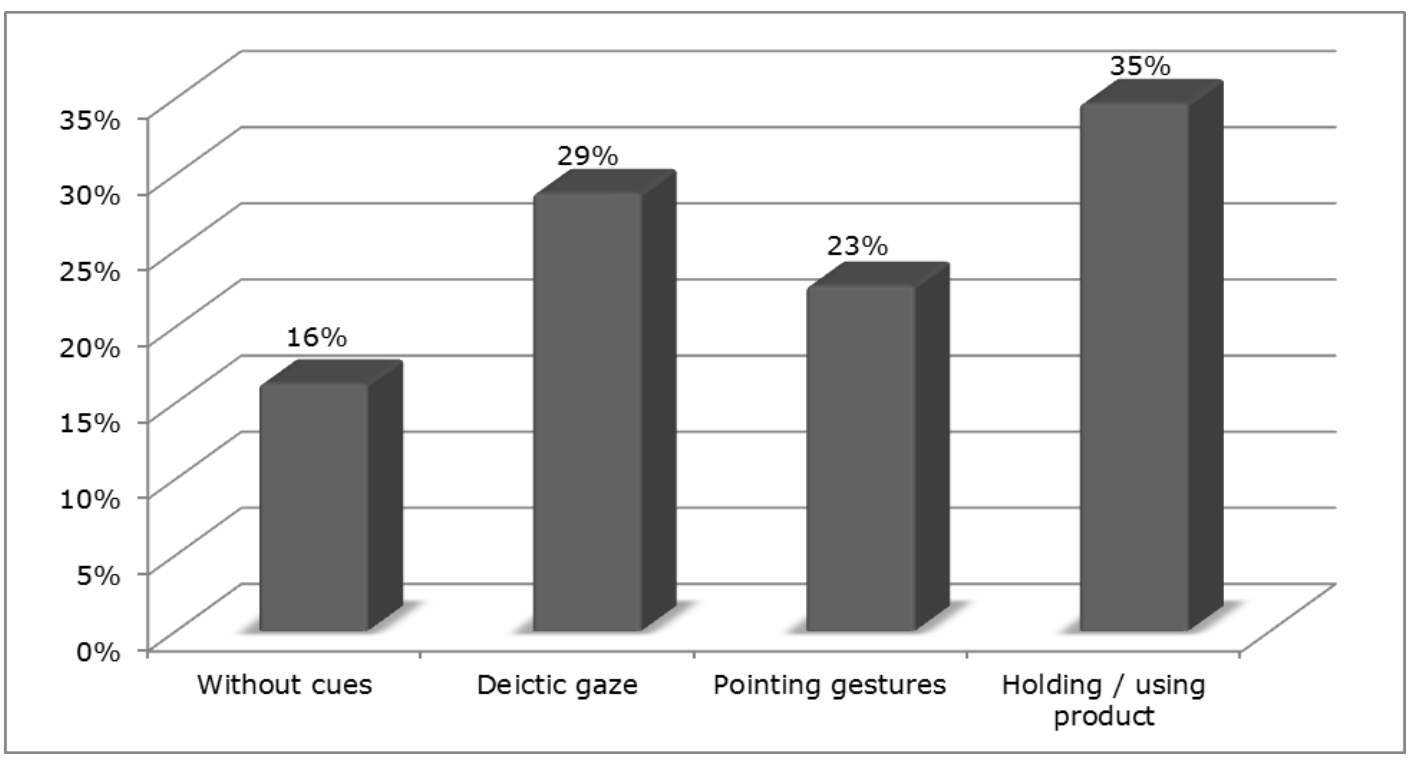

Source: author's elaboration

Fig. 4. Percent of brand viewing time from the advertisement's viewing time

As the data of brand viewing time (total fixation duration) violated the assumptions necessary to run the ANOVA with repeated measures (data has marked deviations from normality and violated Sphericity), Friedman test is applied to test for differences in brand viewing time with different visual cues presented in the advertisements. As it can be seen from Table 2, there is a statistically significant difference in brand viewing time depending on which type of visual cue was applied in the advertisement, $\chi^{2}(3)=15.857, p=0.001$.

Table 2

Friedman Test Statistics

\begin{tabular}{|c|c|c|c|c|}
\hline Variables for Total fixation duration & Mean Rank & Chi-Square & df & p-value \\
\hline Brand in the advertisements without cues & 1.67 & \multirow{4}{*}{15.857} & \multirow{4}{*}{3} & \multirow{4}{*}{0.001} \\
\hline Brand in the advertisements with deictic gaze & 2.83 & & & \\
\hline Brand in the advertisements with pointing gestures & 2.00 & & & \\
\hline $\begin{array}{l}\text { Brand in the advertisements with holding/using } \\
\text { product }\end{array}$ & 3.50 & & & \\
\hline
\end{tabular}

To examine where the differences actually occur, Wilcoxon signed-rank test with the use of Bonferroni adjustment is applied as a Post Hoc test. As there are 6 tests, new significance level is 0.008 (standard significance level of 0.05 divided by the number of tests). The results of Wilcoxon signed-rank test are provided in Table 3 below. As it can be seen from the results, brand presented in the advertisement with visual cue of deictic gaze attracts statistically significantly more visual attention than brand presented in the advertisement without visual cues $(Z=-2.812, p=0.005)$. Moreover, brand presented in the advertisement with visual cue of spokesperson holding / using the product attracts statistically significantly more visual attention than brand presented in the advertisement without visual cues $(Z=-2.831, p=0.005)$. Nevertheless, there is no significant differences between visual attention to the brand presented in the advertisement with pointing gestures and brand presented in the advertisement without visual cues $(Z=-0.971, p=0.331)$; between visual attention to the brand presented in the advertisement with pointing gestures and 
brand presented in the advertisement with deictic gaze $(Z=-2.096, p=0.036)$; between visual attention to the brand presented in the advertisement with holding / using the product and brand presented in the advertisement with deictic gaze $(Z=-2.516, p=0.012)$; and between visual attention to the brand presented in the advertisement with holding / using the product and brand presented in the advertisement with pointing gestures $(Z=-2.516, p=0.012)$. Hence, it could be stated that brand viewing time when applying visual cues of deictic gaze or spokesperson holding / using the product is statistically significantly higher than brand viewing time in the advertisement without visual cues.

Wilcoxon Signed Ranks Test Statistics

Table 3

\begin{tabular}{|l|c|c|}
\hline \multicolumn{1}{|c|}{ Variables for Total fixation duration } & $\mathbf{Z}$ & $\mathbf{p}$-value \\
\hline $\begin{array}{l}\text { Brand in the advertisements with deictic gaze - Brand in the advertisements } \\
\text { without cues }\end{array}$ & -2.812 & $\mathbf{0 . 0 0 5}$ \\
\hline $\begin{array}{l}\text { Brand in the advertisements with pointing gestures - Brand in the advertisements } \\
\text { without cues }\end{array}$ & -0.971 & 0.331 \\
\hline $\begin{array}{l}\text { Brand in the advertisements with holding/using product - Brand in the } \\
\text { advertisements without cues }\end{array}$ & -2.831 & $\mathbf{0} .005$ \\
\hline $\begin{array}{l}\text { Brand in the advertisements with pointing gestures - Brand in the advertisements } \\
\text { with deictic gaze }\end{array}$ & -2.096 & 0.036 \\
\hline $\begin{array}{l}\text { Brand in the advertisements with holding/using product - Brand in the } \\
\text { advertisements with deictic gaze }\end{array}$ & -2.516 & 0.012 \\
\hline $\begin{array}{l}\text { Brand in the advertisements with holding/using product - Brand in the } \\
\text { advertisements with pointing gestures }\end{array}$ & -2.516 & 0.012 \\
\hline
\end{tabular}

Source: author's calculations

This conclusion is substantiated by the analysis of visual attention to the brand regarding all of the separate experiment's advertisements (see Figure 5).

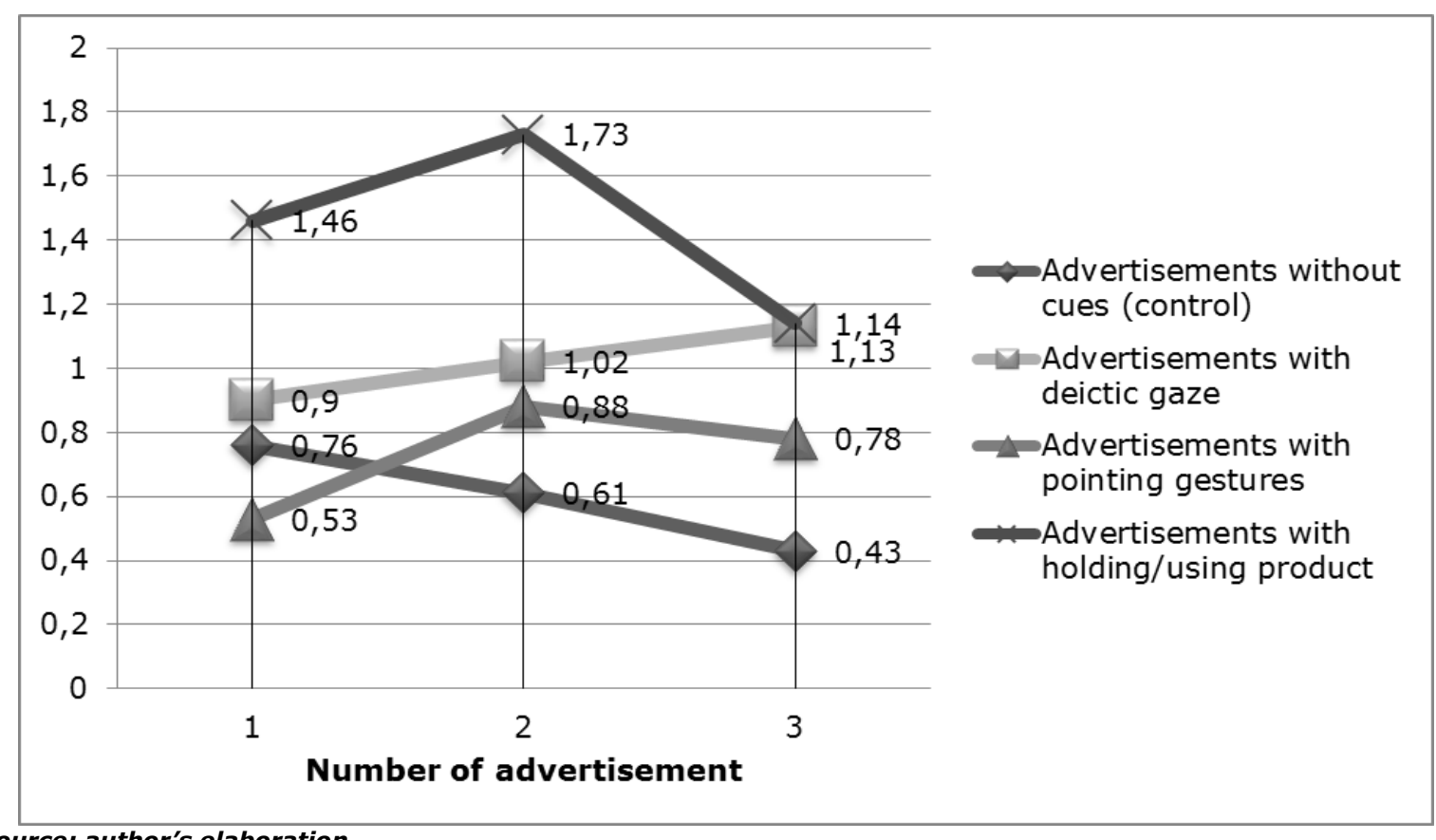

Source: author's elaboration

Fig. 5. Total fixation duration (in seconds) on the brands for different advertisements

As it can be seen, the first advertisement attracted most visual attention to the brand when visual cue of spokesperson holding / using the product or deictic gaze was applied. The same situation is with the second advertisement. Regarding the third advertisements, the application of 
visual cue of spokesperson holding / using the product and deictic gaze attracted nearly the same visual attention to the brand.

In the advertisements without visual cues brand attracted the least visual attention in 2 out of 3 separate advertisements. As it could be seen, regarding the first advertisement where spokesperson was pointing with hand to the product with the brand on it, brand attracted the least visual attention. Nevertheless, in the case of the second and third advertisements, where arrow was pointing from the spokes-character to the product with the brand on it and spokesperson was pointing with leg to the product with the brand on it, brands in the advertisements without visual cues attracted less visual attention when compared to the advertisements with pointing gestures.

\section{Conclusions, proposals, recommendations}

1) The analysis of the research results allows concluding that the core message of the advertisement - the brand - requires additional instruments to make it visible and perceived by consumers in order to enhance brand value. The directional visual cues can serve as an effective instrument to direct consumer's attention to the most important areas (in most cases - the brand) of an advertisement.

2) The analysis of the research results reveal that the highest probability to attract most consumer attention to the brand is to apply visual cue of spokesperson holding / using the product. However, if there are any constrains for application of this type of cue, deictic gaze can be effective as well.

3) The results of the research show that most ineffective (in terms of capturing consumer attention to a brand) are the advertisements where no visual cues are provided.

4) Using pointing gestures as a visual cue is better than leaving an advertisement without a cue; however, the effect of this technique is very low.

\section{Bibliography}

17. Birmingham, E., Bischof, W. F. and Kingstone, A. (2009). Get real! Resolving the Debate About Equivalent Social Stimuli. Visual Cognition, Volume 17, No. 6/7, pp. 904-924.

18. Chamblee, R., Sandler, D. M. (1992). Business-to-Business Advertising: Which Layout Style Works Best?. Journal Of Advertising Research, Volume 32, No.6, pp. 39-46.

19. Eisend, M., Tarrahi, F. (2016). The Effectiveness of Advertising: A Meta-Meta-Analysis of Advertising Inputs and Outcomes. Journal of Advertising, Volume 45, No. 4, pp. 519-531. doi:10.1080/00913367.2016.1185981

20. Hutton, S. B., Nolte, S. (2011). The Effect of Gaze Cues on Attention to Print Advertisements. Applied Cognitive Psychology, Volume 25, pp. 887-892.

21. Patrick, V. M., Hagtvedt, H. (2011). Advertising with Art: Creative Visuals, Editor(s): Mark A. Runco, Steven R. Pritzker, Encyclopedia of Creativity (Second Edition), Academic Press, pp. 18-23. Available from: https://doi.org/10.1016/B978-0-12-375038-9.00003-0.

22. Pileliene, L., Grigaliunaite, V. (2016). Effect of Visual Advertising Complexity on Consumers' Attention. International Journal of Management, Accounting and Economics, Volume 3, No. 8, pp. 489-501.

23. Pileliene, L., Grigaliunaite, V. (2016) Influence of Print Advertising Layout Complexity on Visual Attention. Eurasian business review, Volume 6, Issue 2, pp. 237-251.

24. Pozharliev, R., Verbeke, W.I., Bagozzi, R.P. (2017). Social Consumer Neuroscience: Neurophysiological Measures of Advertising Effectiveness in a Social Context. Journal of Advertising, Volume 46, No. 3, pp. 351-362. Available from: 10.1080/00913367.2017.1343162.

25. Shepherd, V. (2010). Following gaze: gaze-following behavior as a window into social cognition. Frontiers in Integrative Neuroscience, Volume 4, Article 5, pp. 1-13. 